\title{
(2) OPEN ACCESS \\ Central airway obstruction treated with initial support by venovenous extracorporeal membrane oxygenation
}

\author{
Kasumi Shirasaki, ${ }^{1}$ Toru Hifumi, ${ }^{2}$ Takashi Kato, ${ }^{3}$ Shinichi Ishimatsu ${ }^{1}$
}

'Department of emergency and critical care medicine, St Luke's International University, Chuoku, Tokyo, Japan

${ }^{2}$ Critical Care Medicine and Trauma, St Luke's International University, Chuo-ku, Tokyo, Japan

${ }^{3}$ Department of general surgery, Okinawa Prefectural Chubu Hospital, Uruma, Okinawa, Japan

Correspondence to Dr Kasumi Shirasaki; r9666ks2happiness@yahoo. co.jp

Accepted 21 February 2021

\section{SUMMARY}

A 24-year-old man with Down syndrome and congenital tracheal stenosis, who had undergone cartilage patch tracheoplasty twice in infancy, was transferred from a local hospital to manage an airway emergency. On arrival, the patient was in severe respiratory distress. Increased airway pressure following endotracheal intubation complicated the administration of mechanical ventilation. CT of the chest showed widespread consolidation and tracheal stenosis $3 \mathrm{~cm}$ above the carina distal to the tip of the endotracheal tube. The diagnosis was tracheal stenosis with type A influenza infection. The patient was transferred to another hospital for initiating venovenous extracorporeal membrane oxygenation (VV-ECMO). Intubation with a $6.0 \mathrm{~mm}$ spiral tube was successful after intraluminal balloon dilatation of the tracheal stenosis. The patient was admitted to the intensive care unit and was weaned off VV-ECMO on day 3 due to improvement in respiratory status. A tracheotomy was performed on day 28 and the tracheal tube was removed on day 41.

\section{BACKGROUND}

Critical central airway obstruction (CAO) has diverse causes and high morbidity and mortality. Its incidence is increasing along with that of lung cancer, but CAO may also have benign causes and has been reported in survivors of congenital diseases, such as congenital tracheal stenosis (CTS). ${ }^{12}$ The Difficult Airway Society guidelines recommend a sequence of interventions, from laryngoscopy and endotracheal tube placement, to a supraglottic airway device, face mask ventilation and cricothyrotomy, to manage CAO. ${ }^{3}$ However, there is no established treatment for management of CAO caused by an obstruction distal to the tip of an endotracheal tube. Venovenous extracorporeal membrane oxygenation (VV-ECMO) has been used to manage patients with $\mathrm{CAO}$, but there are no reports on patients' benign conditions with involvement of the distal trachea. ${ }^{4}$ This patient, who presented with critical CAO caused by CTS and complicated by influenza A infection, recovered with VV-ECMO support. To the best of our knowledge, this is the first report of the successful use of VV-ECMO support in a patient with CTS.

\section{CASE PRESENTATION}

A-24-year-old man with Down syndrome, CTS and a history of cartilage patch tracheoplasty twice in infancy was transferred from a local hospital to manage an airway emergency. Four days before presentation, he was diagnosed with influenza A and prescribed oseltamivir phosphate. On arrival at the emergency department, the patient was in severe respiratory distress and had an oxygen saturation of $70 \%$ while on supplemental $100 \%$ oxygen with a reservoir mask at $15 \mathrm{~L} / \mathrm{min}$. The patient was intubated for mechanical ventilation, and wheezing was heard on auscultation during both inspiration and expiration. CT of the chest showed widespread consolidation in the right lower lobe and a tracheal obstruction $3 \mathrm{~cm}$ above the carina (figure 1A,B). The airway pressure was elevated due to the tracheal stenosis, which complicated the delivery of mechanical ventilation. Following the diagnosis of influenza A, the patient was transferred to another hospital for VV-ECMO. The patient was intubated with a $6.0 \mathrm{~mm}$ spiral tube after intraluminal balloon dilatation of the tracheal obstruction and was then admitted to the intensive care unit. Deep sedation was maintained with fentanyl, propofol and rocuronium, and ceftriaxone, vancomycin and azithromycin were prescribed for pneumonia. The causative bacteria was identified to be Streptococcus pneumoniae. Hydrocortisone at a dose of $200 \mathrm{mg} /$ day was administered for the first 4 days. The patient

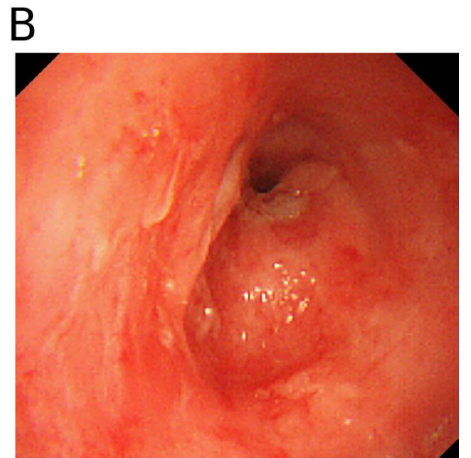

Figure 1 (A) CT and (B) bronchoscope performed on admission. 


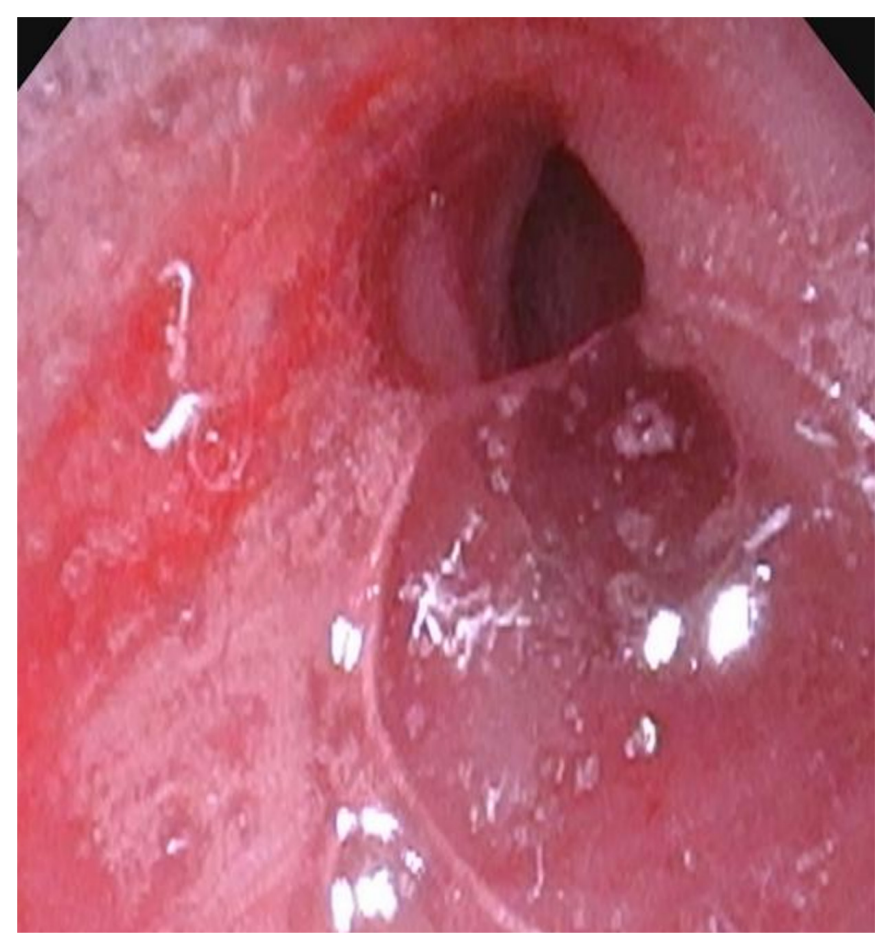

Figure 2 Bronchoscope performed on discharge.

was weaned from VV-ECMO on day 3 following evidence of improvement on chest X-rays. On day 10, the tracheal tube was moved proximally from the stenosis, but tidal volume could not be maintained because the distal end of the tube contacted the stenosis. The tube was reinserted and mechanical ventilation was continued. Tracheostomy was performed on day 28, removal of the tracheal tube was performed on day 41, and the patient resumed oral feeding (figure 2). He was discharged on day 45 .

\section{OUTCOME AND FOLLOW-UP}

One year later, the patient was infected with influenza A and died of respiratory failure.

\section{DISCUSSION}

In this patient, a severe infection caused oedema of the tracheal mucosa, which caused an obstruction resulting in acute respiratory failure. It was difficult to maintain ventilator support because the obstruction was distal to the tip of the endotracheal tube. VV-ECMO was used as a bridge to support the patient until the CAO resolved and oxygenation stabilised; in addition, tracheal stent placement, tracheoplasty and bronchoscopic balloon dilatation were considered to manage the obstruction. ${ }^{5}$ Bronchoscopic balloon dilatation was selected because placing a tracheal stent for a benign stenosis increases the risk of restenosis, and the patient was not a candidate for restenosis surgery due to history of repeated tracheoplasty. ${ }^{6}$ The patient was weaned from VV-ECMO on day 3 because his respiratory status had improved. Withdrawal of the tracheal tube to a position proximal to stenosis was not possible because the distance between the tracheal stenosis and the larynx was short, causing an instability of airway flow during ventilation. Consequently, the endotracheal tube was returned to the original position distal to the stenosis. Tracheal intubation was maintained for 2 weeks. A tracheostomy was performed at that time, and a tracheostomy tube was passed through the stenosis. In the absence of specific treatment guidelines, the tracheostomy tube was removed after 2 weeks following consultation with paediatric surgeons and because bronchoscopy confirmed improvement of the stenosis. Because long-term effectiveness of intraluminal balloon dilatation has not been fully evaluated, ${ }^{78}$ close observation for restenosis is required after recovery in these patients. The prompt initiation of VV-ECMO established and stabilised adequate oxygenation. VV-ECMO was not a treatment of the underlying disease, but provided valuable time for considering the available treatment options.

\section{Learning points}

- Prompt treatment with venovenous extracorporeal membrane oxygenation (VV-ECMO) is required to manage critical central airway obstruction (CAO).

- VV-ECMO should be maintained until non-surgical resolution of the underlying cause.

- The treatment course of this patient highlights the need for improving the existing guidelines for CAO management on presentation to the emergency department.

Contributors KS contributed to project conception, writing and manuscript preparation — writing the majority of the initial draft as well as contributing to the draft. TK was actively involved in decision making and patient treatment. TH and SI played a significant part in the write-up of the manuscript.

Funding The authors have not declared a specific grant for this research from any funding agency in the public, commercial or not-for-profit sectors.

Competing interests None declared.

Patient consent for publication Parental/guardian consent obtained.

Provenance and peer review Not commissioned; externally peer reviewed.

Open access This is an open access article distributed in accordance with the Creative Commons Attribution Non Commercial (CC BY-NC 4.0) license, which permits others to distribute, remix, adapt, build upon this work non-commercially, and license their derivative works on different terms, provided the original work is properly cited and the use is non-commercial. See: http://creativecommons.org/ licenses/by-nc/4.0/.

\section{REFERENCES}

1 Ernst A, Feller-Kopman D, Becker HD, et al. Central airway obstruction. Am J Respir Crit Care Med 2004;169:1278-97.

2 Holden VK, Channick CL. Management of benign central airway obstruction. AME Med J 2018;3:76.

3 Frerk C, Mitchell VS, McNarry AF. Difficult airway Society intubation guidelines Working Group. difficult airway Society 2015 guidelines for management of unanticipated difficult intubation in adults. Br J Anaesth 2015;115:827-48.

4 Park J-H, Shin JH, Kim KY, et al. Respiratory support with venovenous extracorporeal membrane oxygenation during stent placement for the palliation of critical airway obstruction: case series analysis. J Thorac Dis 2017:9:2599-607.

5 Varela P, Torre M, Schweiger C, et al. Congenital tracheal malformations. Pediatr Surg Int 2018:34:701-13.

$6 \mathrm{Xu} \mathrm{X,} \mathrm{Li} \mathrm{D,} \mathrm{Zhao} \mathrm{S,} \mathrm{et} \mathrm{al.} \mathrm{Treatment} \mathrm{of} \mathrm{congenital} \mathrm{tracheal} \mathrm{stenosis} \mathrm{by} \mathrm{balloon-expandable}$ metallic stents in paediatric intensive care unit. Interact Cardiovasc Thorac Surg 2012;14:548-50.

7 Hebra A, Powell DD, Smith CD, et al. Balloon tracheoplasty in children: results of a 15-year experience. J Pediatr Surg 1991;26:957-61.

8 Bagwell CE, Talbert JL, Tepas JJ. Balloon dilatation of long-segment tracheal stenoses. J Pediatr Surg 1991;26:153-9. 
Copyright 2021 BMJ Publishing Group. All rights reserved. For permission to reuse any of this content visit https://www.bmj.com/company/products-services/rights-and-licensing/permissions/

BMJ Case Report Fellows may re-use this article for personal use and teaching without any further permission.

Become a Fellow of BMJ Case Reports today and you can:

- Submit as many cases as you like

Enjoy fast sympathetic peer review and rapid publication of accepted articles

Access all the published articles

Re-use any of the published material for personal use and teaching without further permission

Customer Service

If you have any further queries about your subscription, please contact our customer services team on +44 (0) 2071111105 or via email at support@bmj.com.

Visit casereports.bmj.com for more articles like this and to become a Fellow 